\title{
Defects of metabolism of fatty acids in the sudden infant death syndrome
}

\author{
A J HOWAT, M J BENNETT, S VARIEND, L SHAW, P C ENGEL
}

\begin{abstract}
Two hundred consecutive cases of the sudden infant death syndrome were reviewed for the presence of fat in the liver; 14 showed diffuse panlobular microvesicular fatty change indistinguishable from that found in Reye's syndrome. Samples of frozen liver were available in five of the 14 cases; histochemical analysis showed well preserved cytochrome oxidase and succinate dehydrogenase activity in all five, uncharacteristic of Reye's syndrome. Fatty acyl-coenzyme A dehydrogenase activity in the liver was assayed biochemically in two of the same five cases with severe hepatic fatty infiltration; both showed a defect in medium chain acyl-coenzyme $A$ dehydrogenase activity using the substrate octanoyl-coenzyme A. Both cases also showed cerebral oedema in association with fatty infiltration of renal tubules, myocardium, and skeletal muscle, characteristic of Reye's syndrome.

It is concluded that diffuse panlobular microvesicular fatty change of the liver in victims of the sudden infant death syndrome, although essentially non-specific, indicates that the state of mitochondrial enzymes should be investigated.
\end{abstract}

\section{Introduction}

A subgroup among cases of the sudden infant death syndrome showed severe fatty infiltration of the liver. ${ }^{1}$ This pathological indicator is also characteristic of both Reye's syndrome ${ }^{23}$ and some inborn errors of metabolism of fatty acids. ${ }^{45}$

Children's Hospital, Sheffield S10 2TH

A J HOWAT, MB, BSC, senior registrar in pathology

M J BENNETT, PHD, MRCPATH, principal biochemist

$S$ VARIEND, MD, MRCPATH, consultant pathologist

Department of Biochemistry, University of Sheffield, Sheffield

L SHAW, BSC, research student

P C ENGEL, MA, DPHIL, senior lecturer

Correspondence to: Dr S Variend.
In Reye's syndrome, an acute childhood illness with vomiting and coma that typically occurs a few days after an apparently mild infection, diffuse fatty infiltration of viscera is accompanied by cerebral oedema. ${ }^{2}$ The pathogenesis is usually attributed to generalised mitochondrial dysfunction caused by a viral or toxic agent in a genetically suceptible host. ${ }^{6}$ The pathological diagnosis rests on evidence of decreased activity of mitochondrial enzymes, most notably succinate dehydrogenase. ${ }^{8}{ }^{9}$ Diagnosis, however, is made often on clinical grounds alone, possibly aided by a liver biopsy showing the typical pattern of fatty change..$^{1011}$

On the other hand, inborn errors of fatty acid metabolism can also present as an illness similar to Reye's syndrome and manifest pathological changes identical with those seen in Reye's syndrome. ${ }^{45}$ Infants with such conditions may die suddenly and unexpectedly ${ }^{5}$ and may be classified on clinical grounds as victims of the sudden infant death syndrome. Some have diffuse fatty infiltration of the viscera and cerebral oedema.12 The differential diagnosis of defects of fatty acid $\beta$-oxidation therefore rests on the finding of a single enzyme deficiency rather than a generalised decrease in all mitochondrial enzymes as seen in Reye's syndrome. ${ }^{12}$

This study was conceived to document the proportion of cases of the sudden infant death syndrome with diffuse fatty change of the liver and to determine whether any of these deaths could have been caused by defects of fatty acid $\beta$ oxidation.

\section{Patients and methods}

Two hundred consecutive infants and children aged 1 month to 2 years who had been classified as having died from the sudden infant death syndrome were selected from the files of this hospital Cryostat sections stained for fat with oil red $\mathrm{O}$ were reviewed together with slides stained with haematoxylin and eosin. Those showing diffuse panlobular microvesicular fatty change were further investigated histochemically for cytochrome oxidase and succinate dehydrogenase activity with standard techniques when frozen liver tissue was available ${ }^{13}$; cryostat sections of kidney, myocardium, and skeletal muscle stained with oil red $\mathrm{O}$ were also reviewed in these cases. Assays of fatty acyl-coenzyme A dehydrogenase activity were performed on frozen liver using techniques previously reported.14 A control group of 10 cases of the sudden infant death syndrome 
without serious liver fat were also examined. Liver samples had been stored at $-80^{\circ} \mathrm{C}$ for up to a year.

\section{Results}

Fourteen cases showed diffuse panlobular fatty change in the liver (fig 1), which generally corresponded with small and large cytoplasmic vacuoles on conventional staining. Frozen liver was available

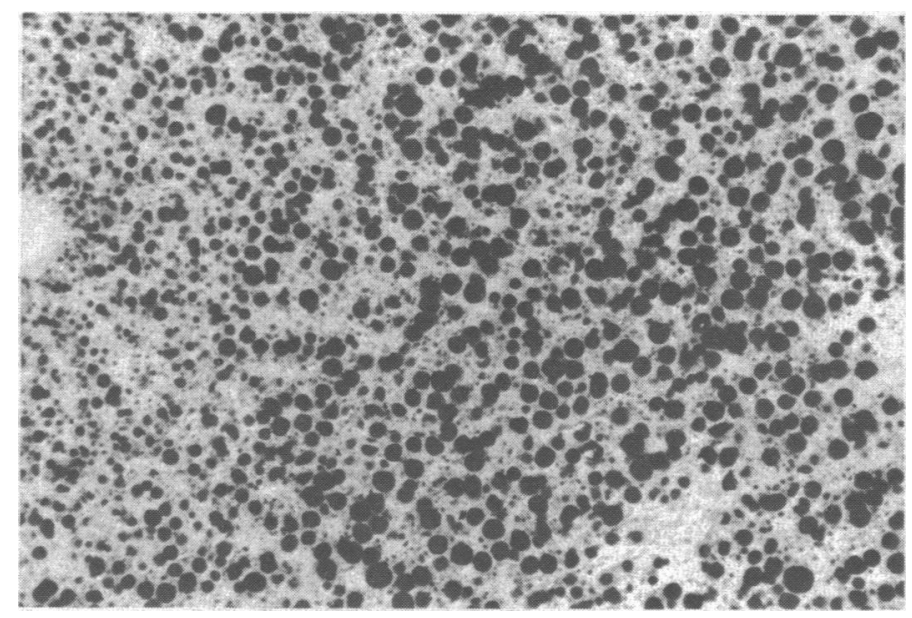

FIG 1-Diffuse panlobular fatty change in liver. Oil red $O \times 360$ (original magnification).

in five cases for enzyme histochemistry. All five showed preservation of cytochrome oxidase and succinate dehydrogenase activity. Table I shows details of two cases with a defect in medium chain acylcoenzyme $A$ dehydrogenase activity using octanoyl-coenzyme $A$ as substrate, with low to normal activity of glutamate dehydrogenase and short and long chain acyl-coenzyme $A$ dehydrogenase. These two cases also showed considerable fatty infiltration of renal tubules, myocardium, and skeletal muscle; these features were also present in the remaining three cases. The control group showed well preserved enzyme activities. Included in table $I$ is the interval between death and necropsy, with postmortem vitreous humour glucose concentrations. Both cases of deficiency of medium chain acylcoenzyme A dehydrogenase showed severe hypoglycaemia. There was no mention of salicylates in the histories of the five cases analysed enzymatically.

\section{Discussion}

An earlier study reported that severe fatty change of the liver occurs in $5 \%$ of cases of sudden infant death ${ }^{1}$; it was suggested that these children had been in some state of "poisoning" or had suffered from an acute metabolic abnormality, such as is seen in Reye's syndrome. Our finding of severe diffuse panlobular fatty change of the liver in $7 \%$ of otherwise unexplained infant deaths agrees with that study.
Included in the mitochondrial damage of Reye's syndrome are enzymes that are thought to act in $\beta$-oxidation of fatty acids; their dysfunction is known to lead to accumulation of intracellular triglyceride. ${ }^{5}$ Exhaustion of glycogen stores due to lack of acetyl-coenzyme A for gluconeogenesis leads to hypoglycaemia. Similar effects and pathological findings are seen in disorders of isolated enzymes that act in fatty acid mitochondrial $\beta$-oxidation. ${ }^{15} 16$ The difference between inborn errors of metabolism and true Reye's syndrome is that the errors are familial whereas Reye's syndrome is, by definition, sporadic.

Those cases of sudden infant death with panlobular fatty change of the liver probably represent a special group in which inherited defects of fatty acid metabolism should be investigated. The incidence of cases of sudden infant death increases from 1:500 live births in the general population to 1:50 in siblings, ${ }^{17}$ which raises the possibility that inborn errors of metabolism may have a role in some such deaths. ${ }^{12}$

The five cases of panlobular fatty change in the liver showed histochemical preservation of cytochrome oxidase and succinate dehydrogenase activity, which argued against a diagnosis of Reye's syndrome. ${ }^{7}$ Two of these cases also showed considerable fatty change of other viscera similar to that described in Reye's syndrome. ${ }^{2}$ Both showed deficiency of medium chain acylcoenzyme A dehydrogenase, an enzyme with a role in the $\beta$-oxidation of fatty acids in mitochondria to produce acetylcoenzyme A (fig 2). The prevalence of such inborn errors of fatty acid metabolism among sudden infant deaths is still unknown.

Besides Reye's syndrome and deficiency of medium chain acyl-coenzyme $\mathbf{A}$ dehydrogenase there are other recognised causes of microvesicular fatty infiltration of the liver, ${ }^{18}$ and hypoglycin and valproate have been shown to inhibit $\beta$-oxidation of fatty acids in animals. ${ }^{19}$ Systemic carnitine deficiency prevents fatty acids from entering the mitochondria for $\beta$-oxidation,

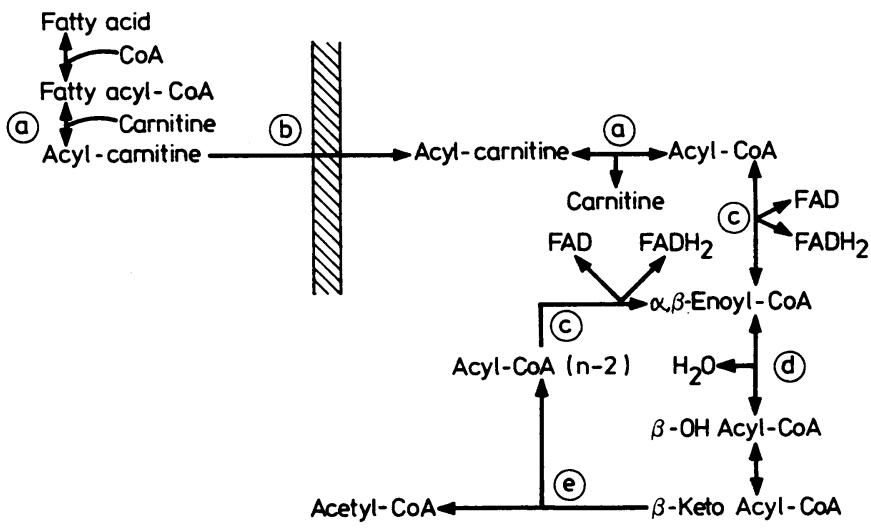

FIG 2-Diagram of mitochondrial $\beta$-oxidation of fatty acids to produce acetyl-coenzyme A. Long chain fatty acids are brought into mitochondria via acyl-carnitine transport mechanism (hatched line represents inner mitochondrial membrane). Enzymes are: (a) acyl-coenzyme A carnitine transferase; (b) acyl-carnitine translocase; (c) acyl-coenzyme A dehydrogenase; $(d)$ enoyl-coenzyme A hydratase; and $(e) \beta$-ketothiolase.

TABLE I-Details of two cases of medium chain acyl-coenzyme A dehydrogenase deficiency compared with 10 cases showing well preserved enzyme activities

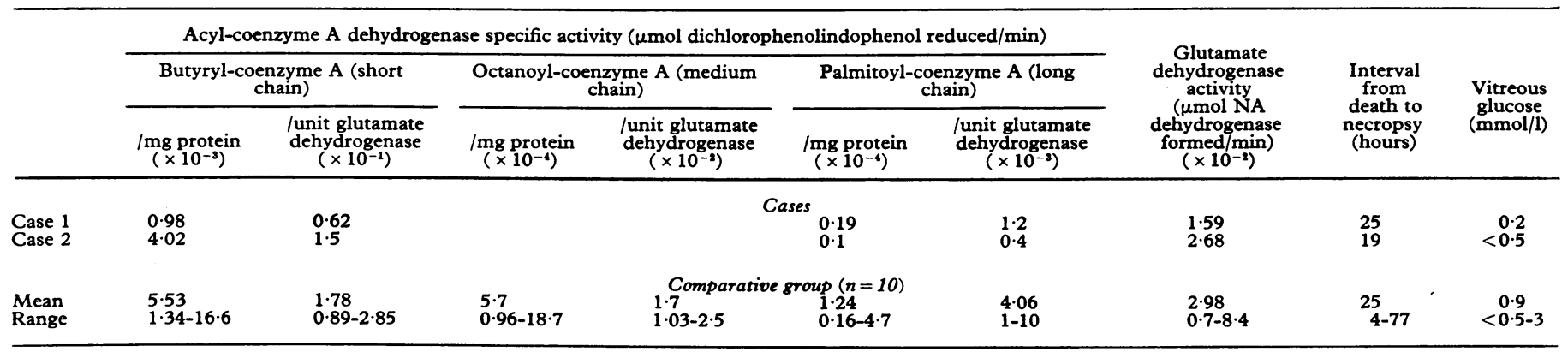


which results in accumulation of intracellular fat. The liver fat in Reye's syndrome is presumably caused by a temporary dysfunction in mitochondrial $\beta$-oxidation. It seems reasonable to assume that cases of sudden infant death with such fatty changes also have abnormalities of fatty acid $\beta$-oxidation, whether congenital or acquired.

Implicit in the currently accepted definition of the sudden infant death syndrome is that necropsy must be thorough to exclude adequate causes of death. ${ }^{20}$ Our findings indicate that all such investigations must include histological examination of the liver, and those livers showing diffuse panlobular fatty change should be further subjected to thorough histochemical and biochemical analysis of the state of mitochondrial enzymes. Conversely, the diagnosis of Reye's syndrome cannot be confirmed by the characteristic liver fatty infiltration without tests for mitochondrial enzyme activity (table II).

TABLE II-Histochemical and biochemical activity of mitochondrial enzymes in Reye's syndrome, medium chain acyl-coenzyme $A$ dehydrogenase deficiency, and sudden infant death syndrome, showing diffuse fatty change of liver

\begin{tabular}{lccc}
\hline \multicolumn{1}{c}{$\begin{array}{c}\text { Enzyme } \\
\text { activities }\end{array}$} & $\begin{array}{c}\text { Reye's } \\
\text { syndrome }\end{array}$ & $\begin{array}{c}\text { Medium change } \\
\text { acyl-coenzyme A } \\
\text { dehydrogenase } \\
\text { deficiency }\end{array}$ & $\begin{array}{c}\text { Fatty change } \\
\text { in sudden } \\
\text { infant death } \\
\text { syndrome* }\end{array}$ \\
\hline $\begin{array}{l}\text { Cytochrome oxidase } \\
\begin{array}{l}\text { Succinate dehydrogenase } \\
\text { Glutamate dehydrogenase }\end{array}\end{array}$ & $\downarrow \downarrow$ & $\begin{array}{c}\text { Normal } \\
\text { Normal }\end{array}$ & $\begin{array}{c}\text { Normal } \\
\text { Normal }\end{array}$ \\
$\begin{array}{l}\text { Short chain acyl-coenzyme A } \\
\text { dehydrogenase }\end{array}$ & $\downarrow \downarrow$ & Normal & $?$ \\
$\begin{array}{l}\text { Medium chain acyl-coenzyme } \\
\text { A dehydrogenase }\end{array}$ & presumed $\downarrow \downarrow$ & $\downarrow$ or normal & $?$ \\
$\begin{array}{l}\text { Long chain acyl-coenzyme A } \\
\text { dehydrogenase }\end{array}$ & presumed $\downarrow \downarrow$ & $\downarrow \downarrow$ & $?$ \\
\hline
\end{tabular}

*Excluding two cases of medium chain acyl-coenzyme A dehydrogenase deficiency.

\section{References}

1 Sinclair-Smith CC, Dinsdale F, Emery JL. Evidence of duration and type of illness in children found unexpectedly dead. Arch Dis Child 1976;51:424-9.

Reye RDK, Morgan G, Baral J. Encephalopathy and fatty degent viscera: a disease entity in childhood. Lancet 1963;ii:749-52.

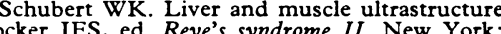
Grune and Stratton, 1979:217-37.

4 Delong GR, Glick TH. Encephalopathy of Reye's syndrome: a review of pathogenetic hypotheses. Pediatrics 1982;69:53-63.

Brandt NJ. Symptoms and signs in organic acidurias. Fournal of Inherited Metabolic Disease 1984;7(suppl 1):23-7.

6 Bellman MH, Hall SM. Aetiology of Reye's syndrome. Arch Dis Child 1983; 58:670-2.

7 Mowat AP. Reye's syndrome: 20 years on. Br Med 7 1983;286:1999-2001.

Bove KE, McAdams AJ, Partin JC, Partin JS, Hug G, Schubert WK. The hepatic lesion in Reye's syndrome. Gastroenterology 1975;69:685-97.

Mitchell RA, Ram ML, Arcinue EL, Chang CH. Comparison of cytosolic and mitochondrial hepatic enzyme alterations in Reye's syndrome. Pediatr Res $1980 ; 14: 1216-2$

10 Corey L, Rubin RJ, Bregman D, Gregg MB. Diagnostic criteria for influenza B-associated Reye's syndrome. Clinical vs pathologic criteria. Pediatrics 1977

11 Hall S, Bellman MH. Reye's syndrome in the British Isles BPA/CDSC surveillance scheme. Communicable Disease Report 1983;39:3-6.

12 Howat AJ, Bennett MJ, Variend S, Shaw L. Deficiency of medium chain fatty cylcoenzyme A dehydrogenase presenting as the sudden infant death syndrome $\mathrm{Br} M$ Med 7 1984;288:976.

13 Filipe MI, Lake BD, eds. Histochemistry in pathology. Edinburgh, London Melbourne, New York: Churchill Livingstone, 1983:318-32.

14 Shaw L, Engel PC. The purification and properties of ox liver short-chain

15 Stanley CA, Hale DE, Coates PM, et al. Medium-chain acyl-CoA dehydrogenase deficies.cy in children with non-ketotic hypoglycemia and low carnitine levels. Pediatr Res 1983;17:877-84.

16 Duran M, De Klerk JBC, Wadman SK, Bruinvis L, Ketting D. The differential diagnosis of dicarboxylic aciduria. Fournal of Inherited Metabolic Disease 1984; (suppl 1):48-51.

17 Peterson DR. Epidemiology of the sudden infant death syndrome: problems, progress and prospects. A review. In: Tildon JT, Roeder LM, Steinschneider A, eds. Sudden infant death syndrome. New York, London: Academic Press, 1983:89-97.

18 Sherlock $S$. Acute fatty liver of pregnancy and the microvesicular fat diseases.

Gut 1983;24:265-9.
Sherratt HSA, Veitch RK. Animal models for dicarboxylic aciduria. fournal of Inherited Metabolic Disease 1984;7(suppl 1):52-6.

20 Bergman AB, Beckwith JB, Ray CG. Proceedings of the second international conference on cause of sudden death in infants. Seattle: University of $W$ ashington

(Accepted 14 March 1985)

\title{
Changes in incidence and prognosis of ischaemic heart disease in Finland: a record linkage study of data on death certificates and hospital records for 1972 and 1981
}

\author{
MARKKU KOSKENVUO, JAAKKO KAPRIO, HEIMO LANGINVAINIO, MATTI ROMO, \\ PEKKA PULKKINEN
}

\begin{abstract}
The components of the decline in mortality from ischaemic heart disease in Finland were studied by analysing the changes in incidence and prognosis between 1972 and 1981. Using personal identification numbers, hospital discharge records and death certificates were linked for all men and women aged 40-64. During this period mortality decreased $15.9 \%$ in men and $23.5 \%$ in women, incidence $14.2 \%$ in men and $19 \cdot 3 \%$ in women, being greatest among 40-49 year olds living in urban areas, and case fatality
\end{abstract}

Department of Public Health Science, University of Helsinki, 00290 Helsinki 29, Finland

MARKKU KOSKENVUO, MD, assistant professor of public health JAAKKO KAPRIO, MD, research assistant of the Finnish Academy HEIMO LANGINVAINIO, $M D$, assistant of public health

MATTI ROMO, MD, docent of public health

PEKKA PULKKINEN, BSC, systems analyst

Correspondence to: Dr Koskenvuo.
$7.3 \%$ in men and $10.3 \%$ in women, owing primarily to a decrease in patients dying of ischaemic heart disease without being admitted to hospital; survival was also better among patients admitted to hospital.

Factors explaining these changes remain unknown because data on risk factors and factors influencing prognosis are limited and largely ecological.

\section{Introduction}

The epidemic of ischaemic heart disease in industrialised countries has been waning in some countries while waxing in others over the past $10-15$ years. ${ }^{1-7}$ Ischaemic heart disease mortality has been declining in Finland since $1969-70$ by a yearly $2 \% \cdot{ }^{8}{ }^{9}$ This decline may be due either to factors improving the prognosis of incident cases or to a decline in incidence of the disease. Because data on changes in incidence of ischaemic heart disease world wide are few we examined data on admission to hospital for and mortality from ischaemic heart disease in Finland for 1972 and 1981 to assess relative changes in mortality, survival, and incidence. 